\title{
EsCola - Ambiente Educacional para Escrita Colaborativa
}

\author{
Euler C. Barros, Crediné Silva de Menezes \\ Laboratório de Informática na Educação - LIED \\ Departamento de Informática - Universidade Federal do Espírito Santo (UFES) \\ Av. Fernando Ferrari, 514, Goiabeiras, 29075-910 - Vitória - ES - Brasil \\ euler.barrosealuno.ufes.br, credinedinf.ufes.br
}

\begin{abstract}
The execution of the pedagogical architecture of collaborative writing of stories using unspecialized collaborative text editing tools overloads the participants by requiring a parallel coordination that is not integrated into the activities execution. This paper presents a tool to support collaboration writing of stories specialized in implementing the pedagogical architecture of collaborative writing.
\end{abstract}

Resumo. A execução da arquitetura pedagógica de escrita colaborativa de histórias utilizando ferramentas de edição de texto colaborativo não especializadas sobrecarrega os participantes por exigir uma coordenação paralela e não integrada à execução das atividades. Esse trabalho apresenta uma ferramenta de apoio à colaboração para escrita de histórias especializada na execução da arquitetura pedagógica de escrita colaborativa.

\section{Introdução}

A criatividade é relevante em qualquer atividade e fundamental instrumento para nortear os avanços científicos [Alencar 2009]. O fomento da criatividade é tema regular na educação e peça fundamental na formação do estudante e pesquisador. Com base nessa tendência, vem ocorrendo uma expansão na oferta de ambientes computacionais para apoio à mais diversas atividades educacionais e colaborativas.

O ambiente proposto por esse trabalho é um software colaborativo especialista voltado para Aprendizagem Colaborativa Apoiada por Computador (CSCL) cujo objetivo é apoiar à atividade de construção colaborativa de histórias.

Segundo [Marek 2007], a colaboração pode ser definida como uma sequência de atividades realizadas por diferentes indivíduos, mas que visam compor um resultado e objetivo em comum. Diferente da cooperação, onde os indivíduos envolvidos nas atividades dividem um mesmo objeto em comum e atuam mutuamente na sua transformação, a colaboração produz pequenos resultados individuais que eventualmente são integrados e compõe a solução final. Esse trabalho se concentra no modelo de colaboração como núcleo das participações e interações dos usuários, sendo essa uma das características marcantes dessa proposta.

Nesse trabalho, a construção colaborativa de histórias se apresenta como uma arquitetura pedagógica cujo propósito está na construção de trechos de um enredo que se desenvolve pela colaboração intercalada de autores. A proposta principal dessa arquitetura é fomentar a criatividade dos participantes em conseguir elaborar sequências 
V Congresso Brasileiro de Informática na Educação (CBIE 2016)

Anais do XXVII Simpósio Brasileiro de Informática na Educação (SBIE 2016)

contextualizadas para a história. Além da criatividade, o exercício da construção colaborativa de histórias também promove melhoria na qualidade da articulação textual dos participantes.

Atualmente existem várias opções de ferramentas computacionais para apoio à atividade de escrita colaborativa. As ferramentas disponíveis se enquadram principalmente na categoria de sistemas generalistas e por isso não objetivam atender aos requisitos específicos da arquitetura pedagógica de escrita colaborativa. A ferramenta proposta por esse trabalho se diferencia por atuar nos requisitos específicos dessa arquitetura pedagógica.

\subsection{Arquitetura pedagógica de escrita colaborativa de histórias}

Uma arquitetura pedagógica é um suporte para aprendizagem que visa unir recursos tecnológicos a estratégias pedagógicas afim de atingir objetivos pedagógicos. Segundo [Nevado 2009] “o caráter das arquiteturas pedagógicas é pensar a aprendizagem como uma construção a partir da vivência de experiências, de reflexões e metarreflexões do sujeito, em interação com o seu meio ambiente sócio-ecológico". As arquiteturas pedagógicas são uma forma do professor utilizar a computação para ampliar a construção do ensino, muitas vezes pela provocação de desequilíbrios cognitivos e propostas de reflexão ativa aos estudantes.

Esse estudo se pauta na arquitetura pedagógica de escrita colaborativa de histórias, que tem por objetivo desenvolver a compreensão na escrita e leitura, fomentar a criatividade e a capacidade de colaboração dos participantes. A criatividade na escrita é habilidade fundamental para todo estudante, seja para elaboração de seus diversos trabalhos ou até mesmo para produções de pesquisa acadêmica. $\mathrm{O}$ desenvolvimento dessa competência se torna então etapa fundamental na formação acadêmica deste, sendo a opção pela aplicação dessa arquitetura pedagógica um meio disponível ao professor para atingir esse objetivo.

A seguir é apresentada a metodologia utilizada nessa pesquisa destacando o foco na produção de um artefato como forma de contribuir para o conhecimento científico.

\section{Metodologia}

Esse trabalho seguiu a metodologia de Design Science Research (DSR), focado na produção da instancia de um artefato que, atendendo aos requisitos levantados diante de um caso vivenciado no mundo real, visa contribuir para o conhecimento científico. De acordo com os tipos de contribuição propostos por [Gregor 2013], esse estudo se classifica no nível 1 (implementação de um artefato para uma situação), se situando como uma melhoria, por proporcionar uma nova solução para um problema já existente e maduro.

\section{Resultados}

Com propósito de apresentação e exercício de conceitos, a arquitetura pedagógica de escrita colaborativa de histórias foi utilizada em uma atividade de uma disciplina de pós-graduação para estudantes do nível de mestrado e doutorado. Inicialmente foram 
V Congresso Brasileiro de Informática na Educação (CBIE 2016)

Anais do XXVII Simpósio Brasileiro de Informática na Educação (SBIE 2016)

apresentadas todas as regras da atividade e os estudantes seguiram todas as etapas envolvidas na execução da arquitetura pedagógica. Por fim, foi proposto uma reflexão aos participantes sobre os pontos positivos e negativos da execução dessa atividade apoiada por uma ferramenta não especializada. Com base nos desafios encontrados, foi proposto um conjunto de requisitos de software de alto nível.

Diante da experimentação da arquitetura pedagógica em aula, foi proposto o seguinte processo geral para execução da mesma.

\subsection{A dinâmica da arquitetura pedagógica}

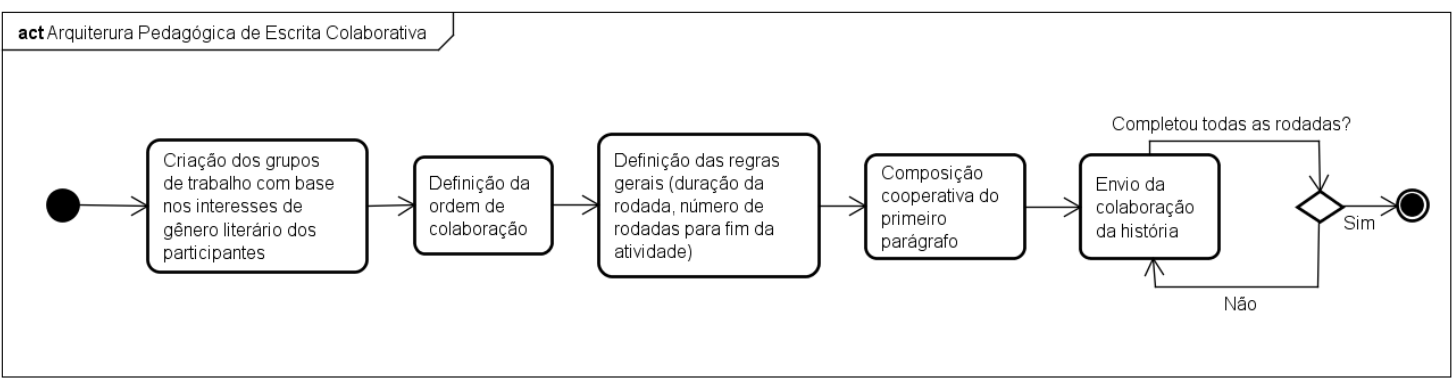

Figura 1 - Diagrama de sequência da arquitetura pedagógica de escrita colaborativa de histórias

O processo se inicia pela listagem dos gêneros literários de interesse dos participantes. Com base nos gêneros levantados e nas preferências pessoais de cada participante, são criados grupos de trabalho. Os grupos de participantes devem ser pequenos (não exceder 12 participantes) de forma a não delongar o período entre duas contribuições de cada participante.

Após definição do grupo de trabalho, deve se definir a ordem de participação dos envolvidos. A atividade irá terminar após um número definido de rodadas. Cada rodada compreende a contribuição de todos os participantes do grupo e cada participante deve contribuir seguindo a ordem definida. Devido ao tamanho pequeno do grupo, é possível que uma rodada seja realizada a cada 24 horas, mas essa duração deverá ser previamente estipulada pelo coordenador da atividade.

Uma vez definida a duração da rodada, obtém-se a janela de contribuição de cada participante. O participante que falhar em enviar sua contribuição dentro do seu período devido, irá para o fim da fila e deverá enviar sua contribuição após o último participante da sequência. Para que um participante possa enviar sua contribuição para a história, ele deverá ter acesso ao estado atual da história, não havendo espaço para questionamentos nem debates sobre o que já foi produzido. De forma geral, não deverá haver comunicação entre os participantes sobre a história em desenvolvimento.

O primeiro parágrafo deve ser escrito de forma síncrona e cooperativa entre todos os participantes do grupo. Após a definição do primeiro parágrafo, inicia-se o ciclo das rodadas de colaboração. 
V Congresso Brasileiro de Informática na Educação (CBIE 2016)

Anais do XXVII Simpósio Brasileiro de Informática na Educação (SBIE 2016)

\subsection{Experimentação da arquitetura pedagógica}

Para apoio na execução dessa arquitetura, os grupos utilizaram a ferramenta Google Docs, por permitir a construção cooperativa e colaborativa de textos de forma simplificada. Por iniciativa dos estudantes, foi acordado a utilização de alguns mecanismos para auxiliar na gestão das rodadas e controle de contribuições.

Foi criada uma tabela para controle das contribuições localizada no topo do texto que estava sendo desenvolvido. A cada colaboração, cabia ao participante atualizar a tabela de controle e avisar o próximo da ordem sobre o início do seu período de contribuição. Durante a execução das rodadas, alguns estudantes extrapolaram o seu período de contribuição e tiveram que aguardar a contribuição de todos os demais participantes antes de poder enviar sua parte.

A execução dessa atividade resultou em sobrecarga a todos os participantes envolvidos, que além de se preocupar em enviar suas contribuições no período acordado, tinham que manter constante controle sobre a ordem de contribuição dos demais participantes. Após o fim da atividade, foi proposto aos alunos envolvidos, o levantamento de requisitos de alto nível que uma ferramenta especialista deveria possuir para facilitar a execução dessa arquitetura pedagógica.

Segue abaixo a relação de requisitos apresentada pelos alunos:

- RQ1: Deve haver uma área especializada para a construção cooperativa do parágrafo inicial;

- RQ2: O aluno deve poder consultar informações sobre o prazo para envio da contribuição e total de rodadas executadas;

- RQ3: Deve ser possível configurar o limite de linhas/caracteres por contribuição (afim de equilibrar as contribuições);

- RQ4: Deve ser possível configurar períodos de envio de novos trechos da história;

- RQ5: Deve ser possível configurar envio de alertas por e-mail dos prazos de contribuição;

- RQ6: Deve ser possível configurar envio por e-mail do relatório de atividades do estudante;

- RQ7: Controle de permissão para observadores (acesso apenas leitura);

- RQ8: Possibilidade de cadastro de mais um professor por turma/grupo;

- RQ9: Possibilidade de comunicação direta e particular entre o professor e o estudante.

\subsection{Ferramentas de edição colaborativa de textos}

Com base nos requisitos apresentados foi feito um levantamento de alternativas de ferramentas que poderiam auxiliar no processo de criação colaborativa de histórias. As ferramentas levantadas oferecem capacidade de edição colaborativa de textos de forma geral e se destacam em pontos específicos. Segue abaixo uma seleção dentre as ferramentas pesquisadas: 
V Congresso Brasileiro de Informática na Educação (CBIE 2016)

Anais do XXVII Simpósio Brasileiro de Informática na Educação (SBIE 2016)

- Google Docs: Ferramenta que permite a criação e edição de texto diretamente pelo navegador. O diferencial dessa ferramenta está no seu acesso gratuito e na sua orientação ao trabalho cooperativo. Usando o Google Docs, é possível a um grupo de usuários escrever sincronamente um texto, o que atende perfeitamente ao primeiro requisito. Os requisitos 7 e 8 também são atendidos por essa ferramenta devido à sua natureza cooperativa. Os demais requisitos levantados não são claramente atendidos por essa ferramenta. Em nossa experiência de aula, escolhemos por usar essa ferramenta devido à sua simplicidade de utilização e atendimento ao primeiro requisito.

- EpA (Escrever para Aprender): Ferramenta que tem por objetivo fundamentar a construção textual com base na comunicação contextualizadas dos participantes. Essa ferramenta permite edição transparente de parágrafos do texto, mas sem descartar os conflitos que surgiram nas edições anteriores. A criação do histórico de versões permite aos demais participantes uma visualização da evolução dos pensamentos e colaborações dos demais colegas, o que proporciona uma aprendizagem indireta, reflexo da observação dos pontos criticados e das medidas tomadas para correção. Apesar de enfocar na construção colaborativa de textos, essa ferramenta é orientada a proporcionar discussões sobre os parágrafos que são produzidos. Devido ao seu foco, ela atende somente aos requisitos 7 e 8 .

- $\quad$ ETC (Editor de Texto Coletivo): Ferramenta que visa oferecer um ambiente para edição de textos focado na colaboração por meio de discussões em formato de fórum. No ETC, as produções dos estudantes são organizadas em pastas, podendo ser compartilhadas publicamente com a comunidade do sistema. Cada pasta pode abrigar também fóruns, de forma a organizar e focar os assuntos discutidos. Apesar dessa solução oferecer um ambiente onde é possível criar e compartilhar textos e discussões, nenhum dos requisitos do domínio levantados é atendido claramente por ela.

A seleção dessas ferramentas visa clarificar a deficiência entre as ferramentas já existentes em atender ao grupo de requisitos específicos da arquitetura pedagógica de escrita colaborativa de histórias. Similar às ferramentas apresentadas, outras opções de ferramentas de apoio à escrita colaborativa existem. Muitas dessas opções se encaixam na categoria de ferramentas generalistas (como é o caso do Google Docs) e não atendem aos requisitos de gestão e coordenação das atividades. Outras são mais especializadas mas objetivam atender demandas particulares de outras propostas pedagógicas. Diante da falta de uma solução que atenda aos requisitos levantados, surge espaço para criação do Ambiente Educacional de Escrita Colaborativa (EsCola). O objetivo principal dessa solução é proporcionar um ambiente educacional de apoio à escrita colaborativa de histórias focado no formato proposto pela arquitetura pedagógica de escrita colaborativa de histórias.

\section{4. $O$ artefato}

O EsCola nasceu da necessidade de apoiar e automatizar a execução da arquitetura pedagógica de escrita colaborativa, facilitando a organização das atividades de 
V Congresso Brasileiro de Informática na Educação (CBIE 2016)

Anais do XXVII Simpósio Brasileiro de Informática na Educação (SBIE 2016)

coordenação que envolvem a execução dessa arquitetura pedagógica. Nesse ambiente, os participantes poderão se concentrar em colaborar na produção textual, deixando a gestão das atividades à cargo do sistema. O EsCola também tem como objetivo proporcionar percepção aos estudantes quanto à sua ordem de contribuição e aos seus prazos para sua efetivação.

O EsCola é composto por uma série de serviços que visam coordenar e facilitar a execução da escrita colaborativa. Utilizando o EsCola, a sequência de atividades para executar essa arquitetura pedagógica ocorre da seguinte forma:

- Configurar atividade: O professor inicia a atividade de escrita colaborativa definindo as regras gerais da dinâmica. Nesse momento o professor pode especificar o total de rodadas para conclusão da história, o limite de caracteres por contribuição do estudante, os prazos para criação do parágrafo inicial, prazo para realização das rodadas, número máximo de estudantes por grupo, entre outras definições. Esse serviço tem como objetivo principal atender aos requisitos 3 e 4 .

- Convite para turma: Após a configuração das regras gerais da atividade, o professor deve registrar o e-mail dos estudantes que irão participar da atividade. Nesse momento é possível também convidar outros professores ou observadores para participarem da atividade. Com esses dados, o sistema envia uma mensagem aos estudantes e participantes os convidando a conhecer o sistema e iniciar a atividade. A princípio, o estudante deve criar um perfil no ambiente informando dados básicos e seus gêneros literários de interesse para escrita. $\mathrm{Na}$ área de configuração de perfil, o estudante pode optar por receber avisos por email sobre os prazos ou relatórios sobre a evolução da história. Esse serviço atende diretamente os requisitos 5, 6, 7 e 8 .

- Organizar participantes: Nesse momento o professor deve criar grupos de trabalho agrupando os estudantes por seus interesses. O sistema oferece uma visão simplificada facilitando a organização dos participantes. Após a definição dos grupos de trabalho, o sistema avisa aos participantes sobre o início das atividades e o prazo do grupo para criação em conjunto do primeiro parágrafo.

- Criação cooperativa do primeiro parágrafo: O ambiente oferece um editor de texto especializado que permite a criação e edição síncrona do texto, com visualização em tempo real das operações realizadas pelos participantes. O editor cooperativo não gera lock no texto, proporcionando uma experiência de interação mais dinâmica. Esse serviço atende ao primeiro requisito levantado.

- Envio da colaboração: Após a criação síncrona e cooperativa do primeiro parágrafo, começa as rodadas de envio das continuidades da história. A cada momento, um estudante do grupo deve enviar sua continuação para a história respeitando a ordem estabelecida pelo professor. O sistema envia alertas para o estudante quando seu turno se inicia. Se um estudante deixa de enviar sua colaboração durante a janela de tempo definida, o turno passa para o próximo estudante da ordem, levando o estudante faltoso para o fim da fila de colaboração. A rodada só termina quando todos os estudantes enviam suas contribuições. Devido à natureza de coordenação desse serviço, esse é o ponto 
V Congresso Brasileiro de Informática na Educação (CBIE 2016)

Anais do XXVII Simpósio Brasileiro de Informática na Educação (SBIE 2016)

onde o sistema se destaca das demais opções de ferramentas de software para a realização dessa arquitetura pedagógica.

- Comunicação direta com o professor: O sistema oferece um quadro de comunicação assíncrona para troca de mensagens com o professor. Esse quadro pode ser utilizado pelo professor para propor reflexões ou apoiar os estudantes em caso de dúvidas sobre o processo. Esse serviço atende ao requisito de número 9.

Os serviços acima foram apresentados seguindo a ordem de execução da arquitetura pedagógica. Além desses serviços, há também uma área de avisos no EsCola onde o estudante pode acompanhar as participações dos colegas e visualizar os prazos que deve se atentar.

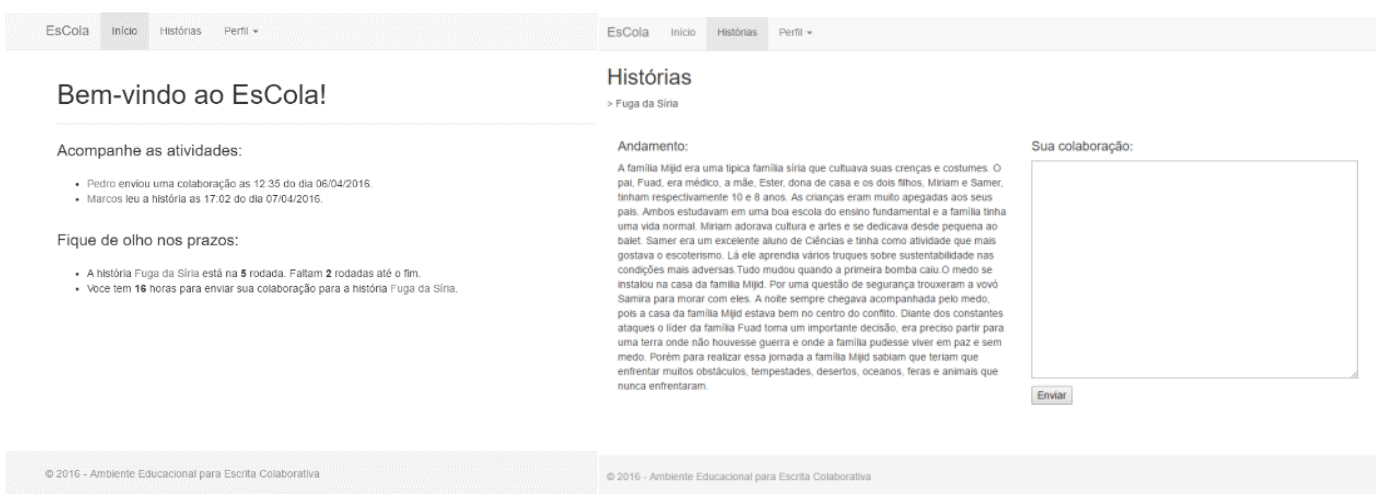

Figura 2 - Principais interfaces com o usuário do sistema EsCola

O EsCola é um ambiente focado em proporcionar percepção aos estudantes que estejam participando de uma atividade de escrita colaborativa. Todos os eventos que impactam nos prazos ou a história são automaticamente informados a todos os participantes do grupo. Devido à essa comunicação frequente, o estudante consegue manter suas colaborações dentro do prazo definido sem se preocupar em ficar visitando o sistema em busca de atualizações.

Ainda assim, para o estudante que opte por não receber as mensagens de aviso e acompanhamento das atividades, é apresentado, na tela inicial do sistema, um quadro com todas os eventos importantes que ocorreram desde a última interação do participante. Dessa forma, essa área atende ao requisito número 2 levantado. A possibilidade de o estudante configurar o seu perfil definindo o seu desejo ou não em receber os avisos por e-mail atende aos requisitos 5 e 6 .

Após o fim da última rodada, a atividade se encerra e o sistema envia para todos os estudantes a compilação da história que foi produzida de forma colaborativa. Essa mensagem final apresenta todo o histórico de colaborações dos estudantes, segmentando o texto por contribuição. São apresentados contadores gerais de participação que visam auxiliar o estudante a identificar e refletir sobre seu processo criativo. 
V Congresso Brasileiro de Informática na Educação (CBIE 2016)

Anais do XXVII Simpósio Brasileiro de Informática na Educação (SBIE 2016)

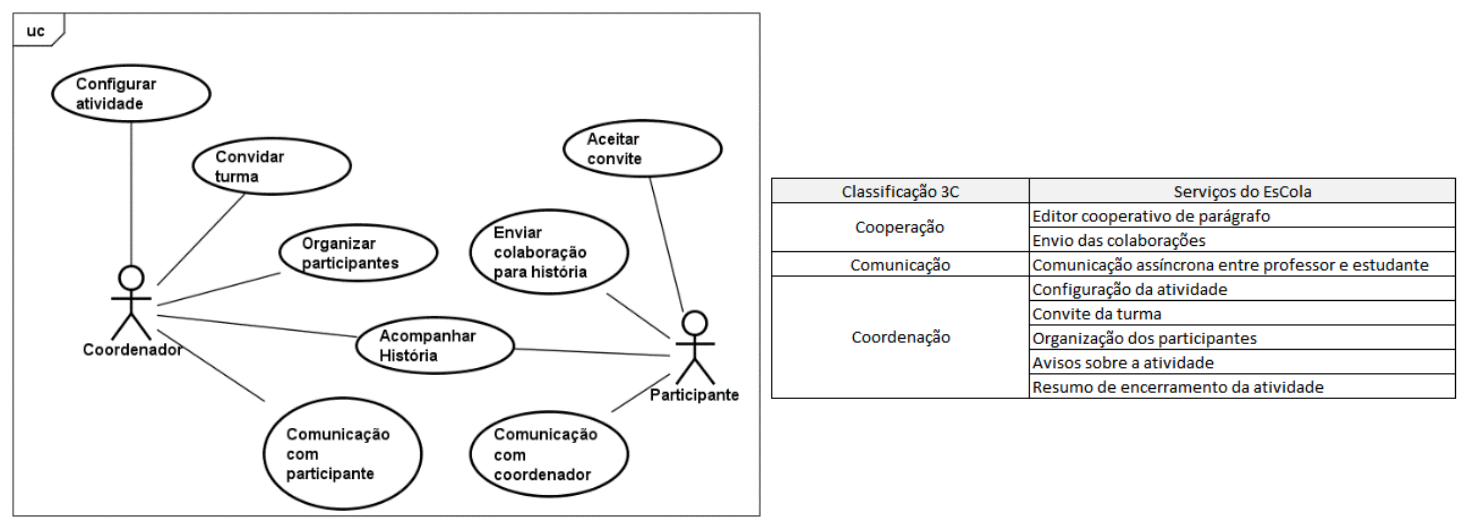

Figura 3 - Diagrama de casos de uso de alto nível do EsCola e classificação dos principais serviços segundo o modelo $3 \mathrm{C}$

A figura 3 apresenta os serviços oferecidos pelo EsCola categorizados segundo a classificação 3C de sistemas colaborativos. [Pimentel 2006]. Vale ressaltar que os serviços críticos do ambiente estão na categoria de coordenação. Essa classificação deixa claro a característica do EsCola em oferecer meios para a organização das atividades do domínio proposto.

\section{Conclusão}

A criatividade e desenvoltura na elaboração de textos é habilidade essencial para todo estudante e pesquisador que almeja publicar seus trabalhos. Nos cursos e disciplinas que apoiam a formação acadêmica sempre há momento específicos dedicados à prática da escrita, como meio a promover a melhoria na qualidade das produções acadêmicas. Um meio de incentivar o estudante a aprimorar sua capacidade de articulação escrita é por meio da aplicação da arquitetura pedagógica de escrita colaborativa de histórias.

Essa arquitetura pedagógica se baseia na construção colaborativa de uma história como forma de incentivar e promover a criatividade dos estudantes. $\mathrm{O}$ trabalho em conjunto de estudante com diferenciados níveis de escrita promove construção e reconstrução de conceitos proporcionando uma evolução na forma de expressão textual dos participantes.

A execução dessa arquitetura pedagógica sem o apoio de uma ferramenta especializada apresenta sobrecarga cognitiva desnecessária e prejudicial para a execução das atividades. Surge então a oportunidade para criação do Ambiente Educacional de Apoio à Escrita Colaborativa - EsCola. Esse sistema visa facilitar a execução da arquitetura pedagógica de escrita colaborativa de histórias por meio da gestão das atividades de coordenação e organização.

Usando o EsCola, os alunos podem se focar diretamente na construção e progresso da história. A ferramenta realiza toda a gestão da execução da atividade deixando o professor livre para a acompanhar de perto as participações dos estudantes e propor questões relevantes para uma evolução personalizada.

A primeira versão do ambiente EsCola visou realizar os requisitos levantados pelos estudantes que vivenciaram a experiência de executar a arquitetura pedagógica de 
V Congresso Brasileiro de Informática na Educação (CBIE 2016)

Anais do XXVII Simpósio Brasileiro de Informática na Educação (SBIE 2016)

escrita colaborativa de histórias sem o apoio de uma ferramenta especializada. Além dos requisitos essenciais levantados, percebeu se a possibilidade de extensão dos serviços ofertados por meio de novos recursos. Segue uma lista de potenciais funcionalidades elencadas para uma próxima versão do sistema:

- Construção de um portal de colaboração: Esse portal iria compreender comunidades de interesse por gênero literário. As produções poderão ser acessadas publicamente por usuários com interesse em participar das rodadas de colaboração.

- Recomendação de conteúdo: Com base no interesse literário dos participantes cadastrados, ao se iniciar novas histórias de gêneros similares, agentes de recomendação podem atuar na comunicação e convite de participação de potenciais participantes.

- Colaboração mobile: Integração da API do EsCola com sistemas de mensagem instantânea móveis pode permitir que os participantes colaborem com a história por meio de serviços de chat como o Telegram¹.

\section{Referências Bibliográficas}

Alencar, Eunice ML Soriano. Medidas de criatividade: teoria e prática. Artmed Editora, 2009.

Axt, Margarete, et al. "ERA UMA VEZ... uma narrativa em co-autoria no espaço virtualco-autoria em narrativa coletivas intersecionadas por tecnologias digitais." Anais do Simpósio Brasileiro de Informática na Educação. Vol. 1. No. 1. 2001.

ETC - Editor de Texto Colaborativo, disponível em http://nuted.ufrgs.br/etc/. Acesso em $07 / 05 / 2016$

Google Docs, disponível em https://docs.google.com/. Acesso em 06/05/2016

Gregor, Shirley, and Alan R. Hevner. "Positioning and Presenting Design Science Research for Maximum Impact." MIS quarterly 37.2 (2013): 337-355.

Lopes, Ana Paula Brandão, et al. "Escrita cooperativa na promoção da aprendizagem." Revista Brasileira de Informática na Educação 14.3 (2006).

Marek, J., et al. "Colaboração e Cooperação: Pertinência, Concorrência ou Complementaridade." Revista Produção On-Line UFSCABEPRO Florianópolis, SC, Brasil 7.3 (2007): 396-401.

Nevado, Rosane Aragón, et al. "Arquitetura pedagógica para construção colaborativa de conceituações." Anais do Workshop de Informática na Educação. 2009.

Peffers, Ken, et al. "A design science research methodology for information systems research." Journal of management information systems 24.3 (2007): 45-77.

Pimentel, Mariano, et al. "Modelo 3C de Colaboração para o desenvolvimento de Sistemas Colaborativos." Anais do III Simpósio Brasileiro de Sistemas Colaborativos (2006): 58-67. 
V Congresso Brasileiro de Informática na Educação (CBIE 2016)

Anais do XXVII Simpósio Brasileiro de Informática na Educação (SBIE 2016)

Sobreira, Elaine Silva Rocha, Maria Cristina Nunes, and Sandra Benedita Morassi. "Produzindo histórias não lineares: um incentivo à produção escrita e leitura, através do uso contextualizado da tecnologia." Anais do Workshop de Informática na Escola. Vol. 1. No. 1. 2013. 